\title{
Personality and Job Satisfaction: The Mediating Role of Job Characteristics
}

\author{
Timothy A. Judge and Joyce E. Bono \\ University of Iowa
}

\author{
Edwin A. Locke \\ University of Maryland
}

\begin{abstract}
This study tested a model of the relationship between core self-evaluations, intrinsic job characteristics, and job satisfaction. Core self-evaluations was assumed to be a broad personality concept manifested in 4 specific traits: self-esteem, generalized self-efficacy, locus of control, and low neuroticism. The model hypothesized that both subjective (perceived) job characteristics and job complexity mediate the relationship between core self-evaluations and job satisfaction. Two studies were conducted to test the model. Results from Study 1 supported the hypothesized model but also suggested that alternative models fit the data well. Results from Study 2 revealed that core self-evaluations measured in childhood and in early adulthood were linked to job satisfaction measured in middle adulthood. Furthermore, in Study 2 job complexity mediated part of the relationship between both assessments of core self-evaluations and job satisfaction.
\end{abstract}

In the decade since Staw, Bell, and Clausen (1986) discovered a link between childhood personality and job satisfaction later in life, there has been considerable interest in the relationship between individual dispositions and job satisfaction. Although this literature has had its critics, an accumulating body of research suggests that variance in job satisfaction across individuals can be traced to measures of affective temperament (House, Shane, \& Herold, 1996; Motowidlo, 1996). There is even evidence that the job satisfaction levels of identical twins reared apart are similar, which suggests a possible genetic basis for job satisfaction (Arvey, Bouchard, Segal, \& Abraham, 1989). More recently, researchers have begun to explore the psychological processes that might underlie dispositional sources of job satisfaction. For example, Weiss and Cropanzano (1996) suggested that affective temperament may influence the experience of emotionally significant events at work, which in turn influence job satisfaction. Similarly, both Brief (1998) and Motowidlo (1996) have recently offered theoretical models in an attempt to illuminate the relationship between dispositions and job satisfaction.

Continuing this theoretical development, Judge, Locke, and Durham (1997) offered a theory linking "core evaluations" of the self to job satisfaction. Judge et al. (1997) defined core selfevaluations as fundamental assessments that individuals make about themselves and their self-worth. Incorporated into their concept of core self-evaluations are four dispositional traits: selfesteem, generalized self-efficacy, locus of control, and low neu-

Timothy A. Judge and Joyce E. Bono, Department of Management and Organizations, Henry B. Tippie College of Business, University of Iowa; Edwin A. Locke, College of Business and Management, University of Maryland.

We thank Terry Boles and Mick Mount for comments on an earlier version of this article.

Correspondence concerning this article should be addressed to Timothy A. Judge, Department of Management and Organizations, Henry B. Tippie College of Business, University of Iowa, Iowa City, Iowa 52242. Electronic mail may be sent to tim-judge@uiowa.edu. roticism. According to Judge et al. (1997), these specific traits indicate a single, higher order factor that they argued forms the basis for other, more specific evaluations. In a test of this theory on three diverse samples, Judge, Locke, Durham, and Kluger (1998) demonstrated that individuals with positive self-evaluations were more likely to assess their job satisfaction at higher levels than individuals with less positive self-evaluations. Furthermore, Judge et al. (1998) found that the link between core self-evaluations and job satisfaction was mediated by perceptions of intrinsic job characteristics. Drawing from Hackman and Oldham (1980), Judge et al. (1998) considered intrinsic job characteristics to include five core job dimensions (identity, variety, feedback, autonomy, and significance). Individuals with positive self-evaluations rated their work as higher on these core dimensions, and thus were more satisfied with their jobs.

Though the Judge et al. (1998) study is a first step toward elucidating the role of intrinsic job characteristics in the relationship between personality and job satisfaction, their findings are limited in that they used only perceptual measures of work characteristics. The job characteristics literature has clearly shown that perceptual measures of intrinsic job characteristics do not perfectly reflect job complexity (Spector \& Jex, 1991). Furthermore, though perceptual measures of job characteristics correlate more highly with job satisfaction than do objective measures, perceptual measures have been criticized for their potential contamination by common method variance (Glick, Jenkins, \& Gupta, 1986). Thus, it is not clear from Judge et al.'s findings to what degree positive self-evaluations are related to increased job complexity as opposed (or in addition) to enhanced perceptions of work characteristics. On the basis of Judge et al.'s research, it is possible that the relationship between core self-evaluations and job characteristics is purely the result of a perceptual process. That is, individuals with positive self-evaluations may see their jobs as more challenging simply because they are predisposed to perceive all aspects of their jobs positively. According to this explanation, there would not be a link between core self-evaluations and the actual characteristics of jobs held (i.e., positive individuals do not really have 
jobs that are more challenging, they simply view their jobs as more challenging). Thus, it is critical to understanding the role of core self-evaluations in job satisfaction to begin to sort out differences in perceptions from differences in actual jobs held.

The purpose of this study was to advance our understanding of the relationship between core self-evaluations, job characteristics, and job satisfaction in several ways. First, we were interested in whether core self-evaluations are linked to objective measures of job complexity - do people with positive core evaluations actually hold more complex jobs? Second, we investigated whether core self-evaluations relate to perceptions of job characteristics once the trait's relationship with objective job characteristics (complexity) is controlled. Finally, we sought to replicate Judge et al. (1998) by using a longitudinal design, which should provide greater confidence in the causal nature and temporal stability of the results. In the following section of this article we develop a hypothesized model of the relationships among core self-evaluations, perceived job characteristics, job complexity, and job satisfaction.

\section{Hypothesized Model}

In an attempt to investigate the degree to which job characteristics are related to core self-evaluations and to satisfaction, we hypothesized a structural model including both direct and indirect relations of core self-evaluations and job characteristics with job satisfaction. Figure 1 contains the hypothesized model. With the exception of the indirect (mediated) relations, each hypothesized relationship in the model is discussed below.

\section{Core Self-Evaluations and Job Complexity}

We are aware of no previous research that has investigated a link between core self-evaluations and job complexity. However, there is some theoretical support for such a link. One source of theoretical support is interactional psychology. As Diener, Larsen, and Emmons (1984) pointed out in developing their interactional theory, individuals seek out situations on the basis of their personological predispositions. Positively disposed individuals experi- ence more objectively positive events in their lives, whereas negatively disposed individuals actually experience more negative events (Magnus, Diener, Fujita, \& Pavot, 1993). As Magnusson (1990) noted, "An individual's view of himself or herself ... with respect to self-evaluation (overall approval and acceptance of himself or herself), plays a central role in the process of interaction with the environment" (p. 201). Thus, it can be argued that individuals with positive core evaluations would be attracted to challenging jobs because they see the potential for greater intrinsic rewards, whereas individuals with a negative self-concept could be expected to focus on the difficulty and potential for failure of challenging work, thus avoiding it.

In addition, Bandura's theory of self-regulation also supports a link between core self-evaluations and job complexity (although it should be noted that Bandura is not a trait theorist). Bandura's theory predicts that individuals' beliefs about their capabilities to perform a task will influence their motivation to seek out or avoid the task. As Bandura (1997) noted, "People avoid activities and environments they believe exceed their capabilities, but they readily undertake activities and pick social environments they judge themselves capable of handling. The higher the perceived self-efficacy, the more challenging the activities they select" (p. 160). Thus, individuals with a positive self-concept should be more willing to take on enriched jobs because they believe in their ability to handle the challenges the job provides. Furthermore, one might also view the link between core self-evaluations and job challenge as the process by which individuals with positive selfconcepts gain control over their work environment, as has been suggested with respect to self-efficacy (Bandura, 1997) and locus of control (Spector, 1982).

There are several other ways in which core self-evaluations may be linked to job complexity. In a test of the impact of self-esteem on goal difficulty, Levy and Baumgardner (1991) found that individuals high in self-esteem chose more difficult goals. These findings were consistent with those of Hall and Foster (1977), who found a relationship not only between self-esteem and goals but also between self-esteem and task involvement (which was related

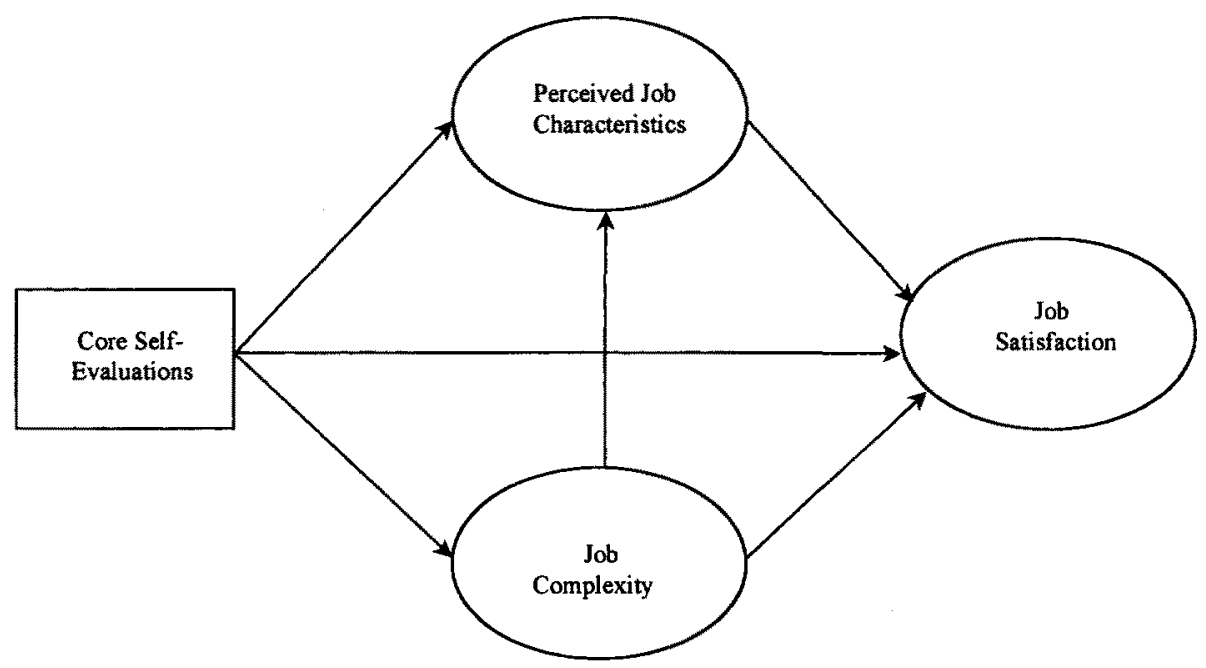

Figure 1. Hypothesized model. All hypothesized linkages are hypothesized to be positive. 
to subsequent goal setting). Lending further support to the notion of a relationship between core self-evaluations and job complexity, Spector (1982) noted that locus of control is related to greater efforts toward goal achievement and perseverance in the face of failure. Because complex jobs implicitly present more challenging goals for individuals, these findings are consistent with a hypothesized link between core self-evaluations and job complexity.

Several of the traits that compose self-evaluations have also been linked to the way individuals cope with complex tasks. For example, Spector (1982) reported that high levels of anxiety (one of the two primary facets of neuroticism) cause individuals to experience performance deficits on complex tasks but not on simple tasks. In addition, both locus of control and self-efficacy have been shown to affect coping and perseverance in the face of obstacles (C. R. Anderson, 1977; Bandura, 1997). Furthermore, there are other, less direct and more long-range ways that core self-evaluations may be related to more complex jobs. Hacket and Betz (1981) found self-efficacy to be an important variable in their career choice model. Although the focus of their work was analyzing the different career choices made by men and women, they found that regardless of gender, self-efficacy within a particular skill set was correlated with interest and entry into careers that required that skill set. Thus, the early socialization experiences and educational preparation of individuals high on core selfevaluations may lead to self-selection into more complex jobs.

In summary, there are a number of ways that core selfevaluations might be expected to be related to job complexity. First, individuals high on core self-evaluations will be more likely to seek out and attempt complex jobs. Second, they might be expected to exert more effort (because of goal-setting activities and higher task involvement) and be less likely to withdraw from complex jobs if they experience failure (because they believe in their abilities). Finally, their high coping skills, particularly for complex tasks, may lead to better performance, resulting in increased attempts to keep and attain more enriched jobs. For these reasons, we hypothesized a positive link between core selfevaluations and job complexity.

\section{Core Self-Evaluations and Perceived Job Characteristics}

There is considerable evidence that perceptions of work characteristics are related to dispositions. Research has shown that positively disposed individuals rate characteristics of the task or the job as more enriched than do less positively disposed individuals (Brief, Butcher, \& Roberson, 1995; James \& Jones, 1980; Judge et al., 1998; Kraiger, Billings, \& Isen, 1989; Necowitz \& Roznowski, 1994). Conceptually, several basic areas of research support the link between personality and perceptions of work characteristics. Research shows that individuals prone to the experience of positive emotions respond favorably to situations designed to induce positive affect, whereas individuals predisposed to experience negative emotions and negative self-appraisals are less likely to respond positively to such situations (Larsen \& Ketelaar, 1991). Similarly, self-verification theory (Swann, SteinSeroussi, \& Giesler, 1992) indicates that individuals seek to verify their self-concepts by selecting situations that will supply them with feedback that reinforces that self-concept. In the job context, Judge et al. (1997) noted that individuals with positive core evaluations might seek out and categorize information in their work environment that would lead to positive conclusions about their work, whereas individuals with negative core self-evaluations might attend to negative aspects of their jobs. Thus, on the basis of previous findings and theoretical support, we expected that core self-evaluations would be related to perceived job characteristics.

\section{Job Complexity and Perceived Job Characteristics}

As noted earlier, there is evidence that the relationship between perceptions of job characteristics and job complexity is not perfect (Spector \& Jex, 1991). However, the existence of a relationship between objective and subjective work characteristics is well established. Fried and Ferris (1987), in their meta-analytic investigation, noted, "The data clearly suggest that objective and perceived job characteristics are related" (p. 309). James and Jones (1980) found support for their hypothesis that perceptions of job characteristics are influenced "causally and positively" (p. 125) by job complexity. Although James and Jones cautioned the reader not to assume that job perceptions represent veridical descriptions of job characteristics, they concluded that objective measures of job complexity do influence perceptions of job characteristics. Furthermore, Gerhart (1988) found that perceptions of job characteristics are a positive function of job complexity. On the basis of these findings, we expected that job complexity would be related to perceived job characteristics.

\section{Perceived Job Characteristics and Job Satisfaction}

The job characteristics model (Hackman \& Oldham, 1980) proposed job satisfaction as one of the essential outcomes resulting from intrinsically enriched jobs. According to the job characteristics model, intrinsic work characteristics positively affect job satisfaction through a perceptual process. Specific job characteristics (e.g., skill variety, task significance) lead to positive psychological states such as feelings of meaningfulness and responsibility, which in turn lead to satisfaction with the job. Research clearly supports the link between perceived work characteristics and job satisfaction. Two meta-analyses indicated a positive, moderately strong correlation between perceptual measures of intrinsic job characteristics and job satisfaction (Fried \& Ferris, 1987; Loher, Noe, Moeller, \& Fitzgerald, 1985). Thus, consistent with Judge et al. (1997), we hypothesized that subjective job characteristics would be positively related to job satisfaction.

\section{Job Complexity and Job Satisfaction}

Although the process of translating job characteristics into job satisfaction is a perceptual one, the job characteristics model assumes that these perceptions originate from job conditions. If this assumption is valid, there should be a positive association between objective measures (i.e., nonperceptual) of work characteristics and job satisfaction. However, there have been few tests of the relationship between job complexity and job satisfaction. Although some studies found only a small relationship between complexity and satisfaction (Spector \& Jex, 1991), Fried and Ferris's (1987) review suggested a consistently positive relationship between objective measures of job characteristics and job satisfaction. Although job complexity explained less of the variance in job satisfaction than did subjective measures of job char- 
acteristics, the relationship was both positive and significant across all studies Fried and Ferris reviewed. On the basis of these small but consistently positive relationships, we hypothesized a direct positive relationship between job complexity and job satisfaction. We note that it is possible that the relationship between job complexity and job satisfaction is entirely mediated through subjective perceptions of job characteristics. Although this explanation seems reasonable, no previous research has investigated this relationship. Thus, we hypothesized a direct relationship between job complexity and job satisfaction, although we did recognize and investigate the possibility that this relationship is mediated by perceived job characteristics.

\section{Core Self-Evaluations and Job Satisfaction}

Consistent with the previous hypotheses, an indirect link from self-evaluations to job satisfaction (mediated by job characteristics) would be expected. However, there is also evidence of a direct relationship between these concepts. Judge et al. (1998) hypothesized and found a direct link between core self-evaluations and job satisfaction. In fact, in most cases the direct relationship was larger than the mediated relationship. A direct link between core self-evaluations and job satisfaction, within the variables measured in this model, is consistent with the direct effects model discussed by Judge et al. (1997). In that model, core selfevaluations influence job satisfaction through a process of emotional generalization--individuals' positive feelings about themselves spill over onto their jobs. To be sure, these direct effects may not be purely direct; they may be mediated by cognitive processes or other mediating variables. However, because this study does not focus on, and thus does not include, cognitive processes or other factors that may mediate the relationship between core self-evaluations and job satisfaction, we hypothesized a direct relationship between core self-evaluations and job satisfaction.

In an effort to investigate the robustness of the hypothesized model, we conducted two separate studies. Because the data collection procedures for each study were quite different, we present separate method and results sections for each study.

\section{Study 1}

\section{Method}

\section{Data and Procedure}

Participants in Study 1 were randomly selected from all zip codes of a midsized midwestern city. In an attempt to minimize the number of surveys sent to households without working adults, we purchased a mailing list that was limited to individuals between the ages of 24 and 58 (excluding most college students and retirees), and with a household income of $\$ 20,000$ or more (so as to exclude those working part time). Surveys were mailed to 1,981 men and women along with a cover letter assuring participants that individual responses were confidential. Included in the mailing was a second survey to be completed by a significant other. Significant others were instructed to complete their surveys away from the focal person and to return it directly to the researchers in a separate postage-paid envelope that was included with the questionnaire. Questionnaires were numbered so that significant-other responses could be matched with those of respondents. In return for their participation, respondents were offered the opportunity to enter their names into a drawing for $\$ 200$.
We received 424 completed surveys from respondents ( 39 surveys were returned as undeliverable), representing a $22 \%$ response rate. We received 389 significant-other surveys, which indicated that for $92 \%$ of the respondents a significant-other survey was also returned. Removal of surveys with missing data resulted in a total of 384 usable responses with 351 matching significant-other reports. Sixty-five percent of significant-other surveys were completed by spouses, with the remaining $35 \%$ completed by siblings $(2 \%)$, parents $(3 \%)$, friends $(21 \%)$, and others $(9 \%)$. No mean difference on any study variable was observed between those respondents who had a significant-other survey returned and those who did not.

The mean age of respondents was 41 years. On average, respondents worked $46 \mathrm{hr}$ per week and had held 1.9 jobs over the past 5 years. Mean annual salary for respondents was $\$ 40,940$. Twenty-four percent of respondents had a high school diploma or less, $55 \%$ had some college or a bachelor's degree, and $21 \%$ had some graduate credit or a graduate degree. Sixty-four percent of respondents were male and $66 \%$ were married. When we compared our sample information to U.S. Census data for the city surveyed, our sample seemed reasonably representative of the working population in terms of age, area of residence (measured by zip code), education level, marital status, and hours worked per week. Members of our sample did earn somewhat higher salaries than indicated by the census data. It is important to note that although our inclusion criteria limited our initial mailing to households with incomes over $\$ 20,000,24 \%$ of the individuals who responded earned incomes of $\$ 20,000$ or less. Nonetheless, it is possible that our sampling procedure produced a somewhat unrepresentative sample, at least with respect to some characteristics.

\section{Measures}

Self-esteem. The first core evaluations trait discussed by Judge et al. (1997) is self-esteem. Self-esteem was measured using Rosenberg's (1965) 10 -item self-esteem scale, which includes items such as "I feel that I am a person of worth, at least on an equal basis with others" and "At times I think I am no good at all" (reverse scored). Scores for individual items, which ranged from 1 (strongly disagree) to 5 (strongly agree), were summed to produce a single self-esteem score for each respondent. Significant others completed these same 10 self-esteem items.

Generalized self-efficacy. As the second core evaluations trait discussed by Judge et al. (1997), generalized self-efficacy was measured using seven items from a scale developed by Judge et al. (1998). Respondents were asked to use a 1 (strongly disagree) to 5 (strongly agree) scale to indicate their level of agreement with statements such as "I am strong enough to overcome life's struggles" and "I often feel that there is nothing that I can do well" (reverse scored). Each individual's scores on the seven items were summed to form a single generalized self-efficacy score. Significant others completed these same seven generalized self-efficacy items.

Locus of control. To measure the locus-of-control component of core self-evaluations, four items measuring internal locus of control were taken from the Internality, Powerful Others, and Chance Scale (Levenson, 1981). Individuals were asked to indicate their agreement with statements regarding the extent to which they have control over events in their lives, such as "When I get what I want, it's usually because I am lucky" (reverse scored) and "My life is determined by my own actions." As with the other core self-evaluations measures, the scale ranged from 1 (strongly disagree) to 5 (strongly agree), with higher scores representing an internal locus of control. Scores for each item were summed to produce a single locus-ofcontrol score for each respondent. For the significant-other survey, these same four items were used.

Neuroticism. To measure the final component of core self-evaluations, neuroticism, we used the 12-item Eysenck Personality Inventory (Eysenck \& Eysenck, 1968) Neuroticism scale. Individuals were asked to indicate their agreement with statements concerning the degree to which they experience feelings of irritability, nervousness, worry, embarrassment, or guilt, such as "I am a nervous person" and "I am a worrier." The same 1-5 
response scale used with the other core self-evaluation traits was used for the Neuroticism scale. Individual items were combined to form a single neuroticism score for each respondent. Significant others completed the same 12 neuroticism items.

Perceived job characteristics. Perceptions of work characteristics (i.e., autonomy, feedback, task variety, identity, and significance) were measured using a 14-item version of the Job Diagnostic Survey (JDS; Hackman \& Oldham, 1980). Respondents were asked to use a scale ranging from 1 (very inaccurate) to 7 (very accurate) to assess the accuracy of statements such as "The job is quite simple and repetitive" (reverse scored) and "The job gives me considerable opportunity for independence and freedom in how I do the work." The JDS was designed to be a multidimensional scale; however, job characteristics measures have been shown to collapse to a single dimension (Dunham, Aldag, \& Brief, 1977). Dunham (1976, p. 408) found that the "most parsimonious factorial solution was a single-factor solution representing job complexity." Also, Loher et al.'s (1985) metaanalytic results support the unidimensional nature of job characteristics measures. Therefore, the 14 individual item responses were summed to form a single perceived job characteristics score for each respondent.

Job complexity. Respondents were asked to report the title of their current job. These job titles were assigned a three-digit occupational code according to the 1970 U.S. Census occupational coding scheme. That census code was converted to a complexity score on the basis of complexity scores derived by Roos and Treiman (1980) from the fourth edition of the Dictionary of Occupational Titles (DOT). Roos and Treiman submitted 46 items from the DOT to exploratory factor analysis and identified a factor they labeled Substantive Complexity.

There are two primary (non-incumbent-based) methods that have been used to assess job complexity. The first is job analysis, a procedure that involves the direct observation of workers and the activities they perform. Although job analysis is the more thorough and complete non-incumbentbased method of rating job complexity, it is not feasible in studies that attempt to assess job complexity across multiple jobs in many organizations. Therefore, consistent with Gerhart (1987), Adelmann (1987), and Spector and Jex (1991), we used the second method, the DOT-based coding for job complexity. One clear advantage to this particular measure of job characteristics is the fact that it is based not on reports of workers or their colleagues but on independent assessments of job descriptions and on-site job observations. However, it should be noted that DOT codes are based on occupations rather than on jobs. For example, the DOT code for police officer represents the average complexity of the job of a police officer across police departments, rather than the job complexity of the specific police officer who responded to our survey. However, reliability estimates for $D O T$ codes are calculated to reflect both interrater agreement and error introduced by aggregating information about several jobs to the occupational level. Results have suggested that there is less variation in complexity across different jobs in the same occupation than across occupations in the same organization, supporting the validity of the DOT measurement system. Psychometric information on the $D O T$ measure can be found in Cain and Green (1983) and Gerhart (1985)

Job satisfaction. We obtained two assessments of job satisfaction. Overall job satisfaction was measured with five items taken from the Brayfield-Rothe (1951) measure of job satisfaction. These five items were "I feel fairly satisfied with my present job," "Most days I am enthusiastic about my work," "Each day at work seems like it will never end" (reverse scored), "I find real enjoyment in my work," and "I consider my job to be rather unpleasant" (reverse scored). Responses to the Brayfield-Rothe items were evaluated on a 1 (strongly disagree) to 7 (strongly agree) scale. In addition, global job satisfaction was also measured using the three-item scale developed by Judge, Boudreau, and Bretz (1994), which includes the nongraphic version of the G. M. Faces Scale (Scarpello \& Campbell, 1983, replaced faces with affective state descriptions), an adapted version of the Fordyce Percent Time Happy Item, and the Gallup Poll measure of job satisfaction. Because these three items were measured using different response formats, they were standardized and combined into a three-item composite measure of job satisfaction.

\section{Covariance Structure Analysis}

Covariance structure analysis, which was estimated in the present study by using LISREL 8 (Jöreskog \& Sörbom, 1993), was used to test the structure of the core self-evaluations concept as well as the hypothesized model. To prevent the interpretational problems inherent in simultaneous estimation of measurement and structural models (J. C. Anderson \& Gerbing, 1988), we used confirmatory factor analysis to test the measurement model separately prior to simultaneous estimation of the measurement and the structural models. The first structural model tested (the self-report model) is based on self-reports of all study variables, with the exception of job complexity. The second model (the mixed data model) is the same as the self-report model, except that significant-other reports of core evaluations were used. The advantage of the mixed data model is that it allows inferences about the relations among the concepts to be mostly free of percept-percept inflation. The relationship between perceived job characteristics and job satisfaction is susceptible to this inflation; however, we considered it impractical to measure these two concepts by any other means.

We specified the structural model by allowing the four core selfevaluation traits to load on a latent factor and the two job satisfaction measures to load on another latent factor (to allow this factor to be identified, one of the loadings was fixed at 1.0). Because perceived job characteristics was measured with a multi-item scale, correction for measurement error was based on its estimated reliability. The reliability of the DOT-based measure of job complexity has been extensively analyzed; we used Cain and Green's (1983) average estimate of interrater reliability (.69) in correcting job complexity for measurement error. In the covariance structure model, the measurement error for all directly observed variables (in Study 1, perceived job characteristics and job complexity; in Study 2, all three variables in the model) was fixed as the variance of the variable times one minus the reliability of the variable.

When interpreting the results of covariance structure analysis, it is important to evaluate the model by using several indices of overall fit. Accordingly, we report the following fit statistics: chi-square, root mean square error of approximation (RSEA), goodness-of-fit index (GFI) normed fit index (NFI), non-normed fit index (NNFI), incremental fit index (IFI), and relative fit index (RFI; Medsker, Williams, \& Holahan, 1994). Although levels of the chi-square statistic cannot be interpreted independently of the sample size, rules of thumb suggest that the RSEA should be no greater than .10, whereas values of GFI, NFI, NNFI, IFI, and RFI should be greater than .90 (Medsker et al., 1994). Finally, we also report two fit statistics that correct for lack of parsimony, the adjusted goodness-of-fit index (AGFI) and the parsimony normed fit index (PNFI). Rules of thumb for judging the latter statistics have not been established.

\section{Results}

\section{Descriptive Statistics, Scale Reliabilities, and Intercorrelations}

Table 1 presents descriptive statistics, scale reliabilities, and intercorrelations of study variables. To permit examination of uncorrected relations among the concepts in the model, also included in Table 1 are two composite core self-evaluations indices (one for self-reports and one for significant-other reports) that were equally weighted combinations of the four core traits and a similar composite index for the two individual measures of job satisfaction. As was the case with Judge et al. (1998), locus of control displayed the lowest correlations with the other core traits 
Table 1

Descriptive Statistics, Scale Reliabilities, and Intercorrelations of Study 1 Variables

\begin{tabular}{|c|c|c|c|c|c|c|c|c|c|c|c|c|c|c|c|c|c|}
\hline Variable & $M$ & $S D$ & 1 & 2 & 3 & 4 & 5 & 6 & 7 & 8 & 9 & 10 & 11 & 12 & 13 & 14 & 15 \\
\hline 1. Self-esteem & 41.52 & 6.29 & 87 & & & & & & & & & & & & & & \\
\hline 2. Generalized self-efficacy & 29.49 & 4.21 & 77 & 86 & & & & & & & & & & & & & \\
\hline 3. Locus of control & 14.95 & 2.51 & 46 & 47 & 70 & & & & & & & & & & & & \\
\hline 4. Neuroticism & 27.14 & 8.59 & -65 & -60 & -29 & 90 & & & & & & & & & & & \\
\hline 5. Core self-evaluations composite & 0.00 & 3.27 & 89 & 88 & 69 & -79 & 84 & & & & & & & & & & \\
\hline 6. Self-esteem, SOR & 41.35 & 6.06 & 44 & 41 & 26 & -41 & 47 & 86 & & & & & & & & & \\
\hline 7. Self-efficacy, SOR & 29.41 & 4.39 & 41 & 40 & 26 & -38 & 45 & 80 & 86 & & & & & & & & \\
\hline 8. Locus of control, SOR & 15.51 & 2.43 & 16 & 15 & 29 & -12 & 22 & 35 & 41 & 70 & & & & & & & \\
\hline 9. Neuroticism, SOR & 26.17 & 8.38 & -33 & -28 & -12 & 50 & -38 & -62 & -58 & -22 & 90 & & & & & & \\
\hline 10. Core self-evaluations composite, SOR & 0.00 & 3.15 & 43 & 39 & 29 & -44 & 48 & 88 & 88 & 63 & -77 & 80 & & & & & \\
\hline 11. Perceived job characteristics & 70.77 & 11.81 & 36 & 36 & 29 & -27 & 39 & 26 & 21 & 13 & -13 & 23 & 73 & & & & \\
\hline 12. Job complexity & 5.13 & 2.11 & 20 & 16 & 13 & -16 & 20 & 24 & 18 & -02 & -19 & 19 & 23 & $69^{\mathrm{a}}$ & & & \\
\hline $\begin{array}{l}\text { 13. Job satisfaction (Brayfield \& Rothe, } \\
\text { 1951) }\end{array}$ & 25.88 & 6.89 & 40 & 31 & 27 & -27 & 39 & 22 & 17 & 12 & -07 & 18 & 59 & 16 & 89 & & \\
\hline 14. Job satisfaction (Judge et al., 1994) & 0.00 & 2.67 & 43 & 32 & 27 & -28 & 40 & 2 & 20 & 11 & -11 & 21 & 59 & 16 & 84 & 86 & \\
\hline 15. Job satisfaction composite & 0.00 & 1.92 & 43 & 33 & 28 & -29 & 41 & 24 & 19 & 12 & -09 & 19 & 62 & 17 & 96 & 96 & 91 \\
\hline
\end{tabular}

Note. Coefficient alpha reliability estimates are on the diagonal. Decimals are omitted from correlations and reliabilities. $N=348$. SOR $=$ significantother reports. $p \leq .05$ at $r=.11 . \quad p \leq .01$ at $r=.14$.

${ }^{a}$ From Cain and Green (1983).

and with the other variables. Correlations between self-reports and significant-other reports of core evaluations were moderate (ranging from .29 for locus of control to .50 for neuroticism). Although it is not reported in Table 1 , it is worth noting that self-other correlations were only slightly $(r=.02)$ higher when the spouse was the significant other. Overall, correlations between study variables were in the direction expected.

\section{Confirmatory Factor Analysis of Core Traits}

To analyze the factor structure of the data, we conducted a second-order factor analysis. (Because similar results were obtained for the significant-other reports of the core traits, for simplicity we confine our discussion to self-reports of the core traits.) In the first stage of the analysis, we created three parcels for each of the core traits. These parcels were formed from the individual scale items (e.g., two of the three self-esteem parcels were formed by adding three randomly selected items from the self-esteem scale, and the third parcel was formed by adding the remaining four items). When each of these parcel sets was constrained to load on its respective traits, results indicated that this model fit the data reasonably well. The fit statistics were as follows: $\chi^{2}(48, N=$ $414)=123.08(p<.01), \mathrm{RSEA}=.06, \mathrm{GFI}=.95, \mathrm{AGFI}=.92$, $\mathrm{NFI}=.96, \mathrm{NNFI}=.96, \mathrm{IFI}=.97, \mathrm{RFI}=.94, \mathrm{PNFI}=.70$. In the second stage of this analysis, following Jöreskog and Sörbom (1989, p. 160), we conducted a second-order factor analysis in which the four core traits contributed to an overall core selfevaluations factor. This second-order model appeared to fit the data acceptably, $\chi^{2}(54, N=414)=159.00(p<.01)$, RSEA $=$ $.07, \mathrm{GFI}=.94, \mathrm{AGFI}=.91, \mathrm{NFI}=.95, \mathrm{NNFI}=.96, \mathrm{IFI}=.96$, RFI $=.94$, PNFI $=.77$. The factor loadings from the first- and second-order factor analyses from the self-report model are displayed in Figure 2.

As the second-order factor analysis results show, self-esteem and self-efficacy were nearly perfectly correlated with the core self-evaluations factor. Furthermore, the parcels for locus of con- trol displayed lower factor loadings than the other core traits, and locus of control contributed less to the core concept. Thus, it might be asked whether locus of control is necessary to form the core self-evaluations concept. As suggested by a reviewer, to test this possibility we constrained the second-order loading involving locus of control to zero. If locus of control contributes little to the core concept, the fit of the model will not be reduced. However, estimation of this model revealed that constraining the locus-ofcontrol second-order loading to zero significantly reduced the fit of the second-order model, $\Delta \chi^{2}(1, N=414)=107.62, p<.01$. Constraining the second-order loadings of the other core traits to zero reduced the fit of the model to an even greater degree. Thus, within the confines of this measurement model, it appears that all four traits are important elements of the core concept, though future research should investigate the adequacy of locus of control in identifying the core self-evaluations concept, which may also require looking at the adequacy of locus-of-control measures.

\section{Structural Model Results}

LISREL estimates for the self-report model, which relates selfreports of the core evaluations to perceived job characteristics and job complexity and to job satisfaction, are provided in the upper row of Figure 3. Results show that core self-evaluations had a moderately strong and significant relationship both with perceptions of job characteristics and with job complexity. Core selfevaluations also displayed a direct relation with job satisfaction. Results also show that job complexity was related to perceived job characteristics. Finally, perceptions of job characteristics and job satisfaction were strongly related, whereas job complexity had no direct relationship with job satisfaction. However, it is important to note that job complexity had a significant indirect relationship to job satisfaction $(r=.13, p<.05)$, as mediated through perceived job characteristics. Fit statistics for the self-report model were as follows: $\chi^{2}(16, N=384)=26.41(p=.05)$, RSEA $=.04$, GFI $=$ 


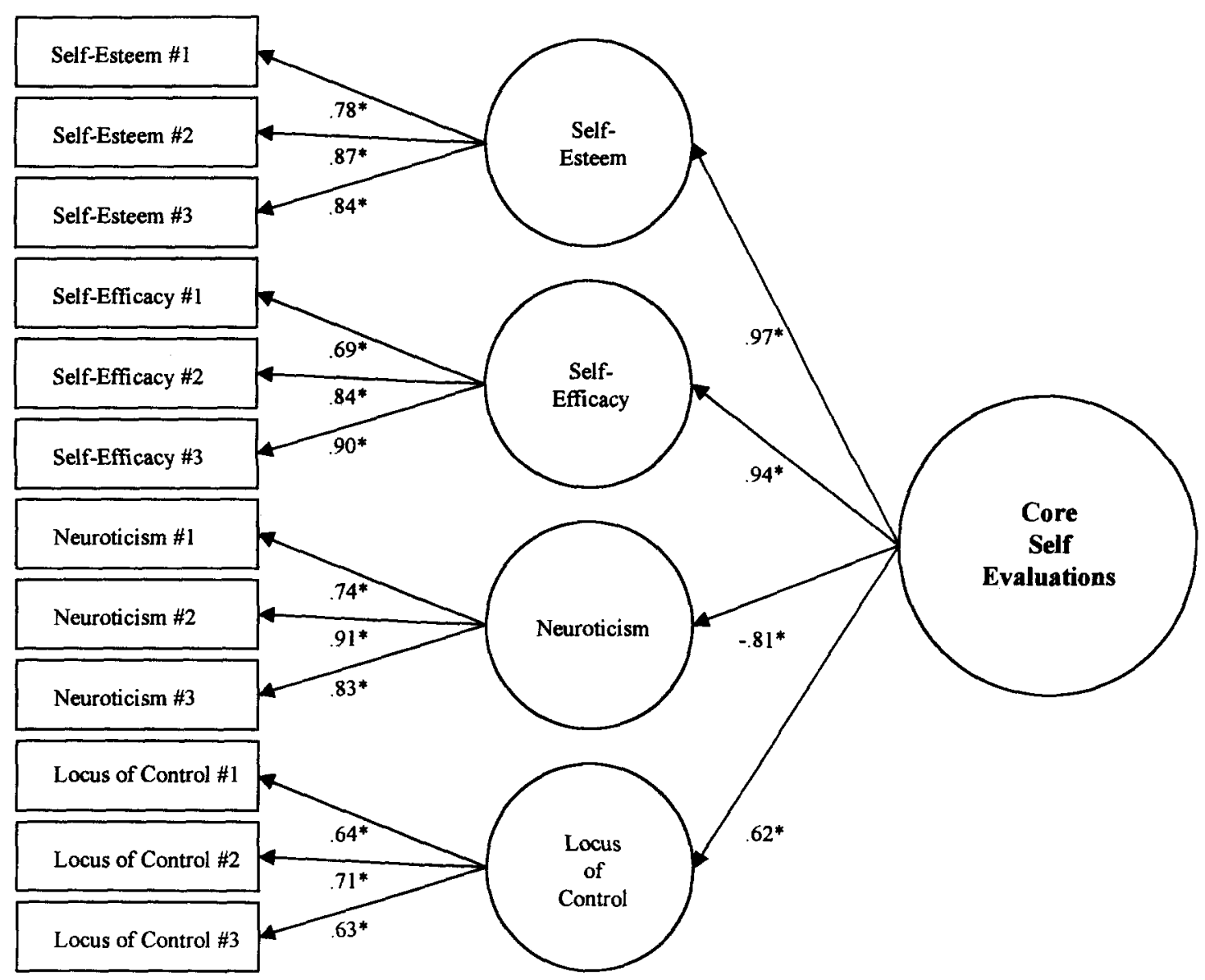

Figure 2. Second-order factor analysis results-self-report data. First-order factor loadings were estimated from first-order factor analysis. $* p<.01$.

$.98, \mathrm{AGFI}=.96, \mathrm{NFI}=.98, \mathrm{NNFI}=.99, \mathrm{IFI}=.99, \mathrm{RFI}=.97$, $\mathrm{PNFI}=.56$.

LISREL estimates for the mixed data model, which relates significant-other reports of the core evaluations to self-reports of job characteristics, job complexity, and job satisfaction, are provided in the lower row of Figure 3. Results show that core evaluations (as reported by significant others) had a significant relationship to job complexity. However, the relationship between core evaluations and perceptions of job characteristics was weaker in this model, leading to the inference that some of the relationship between core evaluations and perceptions of work characteristics in the self-report model may be based on common method variance. Another difference from the self-report model was that core self-evaluations no longer had a significant direct relationship with job satisfaction. Results also show that job complexity had a relationship, in this model, with perceptions of job characteristics similar to that found in the self-report model. Finally, consistent with the self-report model, perceptions of work characteristics and job satisfaction were strongly related, whereas job complexity had no direct relationship with job satisfaction. However, as in the self-report model, job complexity had a significant indirect relationship with job satisfaction $(r=.19, p<.05)$ as mediated through perceived job characteristics. Fit statistics for the mixed data model were comparable to those of the self-report model, $\chi^{2}(16, N=351)=21.95(n s)$, RSEA $=.03, \mathrm{GFI}=.98, \mathrm{AGFI}=$ $.96, \mathrm{NFI}=.98, \mathrm{NNFI}=.99, \mathrm{IFI}=1.00, \mathrm{RFI}=.97, \mathrm{PNFI}=.56$.

The second and third columns of Table 2 contain the direct, indirect, and total (direct + indirect) relationships of core selfevaluations with job satisfaction for the self-report and mixed data models, respectively. The results show that most of the significant relationship between core self-evaluations and job satisfaction was mediated by perceived job characteristics and job complexity. Given the presence of significant indirect relationships and the fact that more than half of the total relationship is mediated, we can infer from these results that job characteristics mediated the relationship between core self-evaluations and job satisfaction.

\section{Alternative Model Tests}

To investigate the validity of the hypothesized model, we considered three alternative models. One alternative model stipulated no direct relationship between core self-evaluations and job satisfaction. This model is plausible if the relationship between core self-evaluations and job satisfaction is entirely mediated by job complexity and perceived job characteristics. A second alternative model stipulated no direct relationship between job complexity 


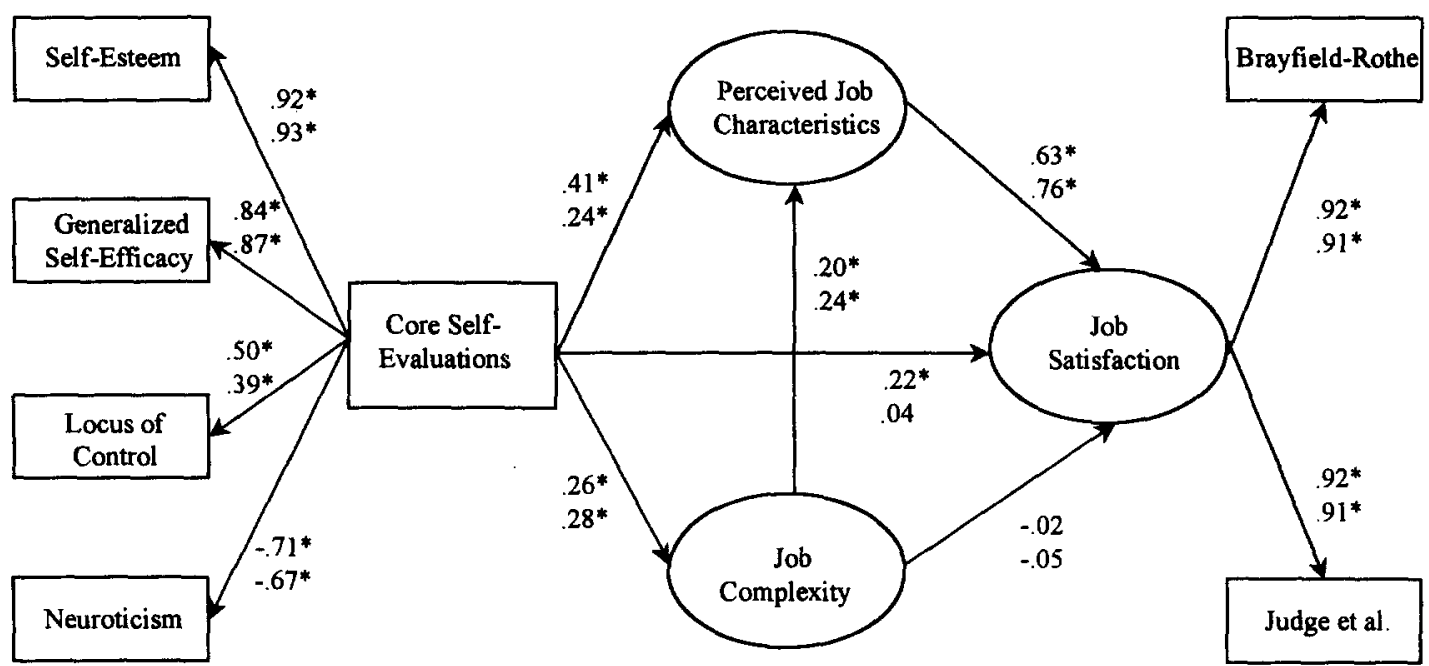

Figure 3. LISREL results-Study 1. Estimates in top row represent results from self-report model; estimates in bottom row represent results from mixed data model. ${ }^{*} p<.01$.

and job satisfaction. This model is also a plausible alternative because it is quite possible that the effects of job complexity are completely mediated through perceptions of those characteristics. Because these more parsimonious models are nested within the hypothesized model, the difference in chi-square between these models can be tested for significance.

The previous two alternative models entailed removing paths to determine whether a more parsimonious model was possible. A third alternative model would posit a different order of relationships, such that job satisfaction mediates the relationship between core self-evaluations and perceived job characteristics (as opposed to the hypothesized model, which hypothesized that perceived job characteristics mediated the relationship between core selfevaluations and job satisfaction). This model is justified in light of research that suggests that the relationship between perceived job characteristics and job satisfaction may be bidirectional or from job satisfaction to perceived job characteristics (James \& Jones, 1980; James \& Tetrick, 1986). This third model would reverse the relationship between perceived job characteristics and job satisfaction, so that job satisfaction influences (rather than is influenced by) perceived job characteristics. Although this model is a reasonable alternative to the hypothesized model, it would fit the data exactly the same as the hypothesized model because it would simply reverse the link between perceived job characteristics and job satisfaction. Thus, it was not tested in this study but is considered in the Discussion section.

In the model that drops the link between core self-evaluations and job satisfaction, results indicate that dropping the link significantly decreased the fit of the model for the self-report model, $\Delta \chi^{2}(1, N=384)=15.38, p<.01$, but not for the mixed data model, $\Delta \chi^{2}(1, N=351)=0.48, n s$. Even though the $\Delta \chi^{2}$ statistic was significant for the self-report model, the other standardized fit statistics showed little difference (the mean difference was .015). Furthermore, the fit statistics that take parsimony into account, AGFI and PNFI, were actually higher for the alternative model (which suggests that the decrease in fit because of the added constraint was more than offset by the increase in parsimony). For the model that drops the link between job complexity and job satisfaction, results indicated that dropping the link did not decrease the fit of the model for either the self-report, $\Delta \chi^{2}(1, N=$ $384)=0.20, n s$, or mixed data, $\Delta \chi^{2}(1, N=351)=0.61, n s$, models. Thus, it appears that two of the direct links in the hypothesized model could be eliminated (thus simplifying the model) without causing it great damage.

\section{Study 2}

Study 2 was conducted in an attempt to examine the extent to which the relationships between core self-evaluations, job characteristics, and job satisfaction are robust over time. This study uses longitudinal data collected over a period of 30 years to test the hypothesized model.

\section{Method}

\section{Data and Procedure}

The data for this study were obtained from the Intergenerational Studies (IGS), administered by the Institute of Human Development, University of

Table 2

Direct, Indirect, and Total Relationships Between Core SelfEvaluations and Job Satisfaction

\begin{tabular}{llllll}
\hline & \multicolumn{2}{c}{ Study 1} & & \multicolumn{2}{c}{ Study 2} \\
\cline { 2 - 3 } \cline { 5 - 6 } \multicolumn{1}{c}{ Relationship } & \multicolumn{2}{c}{$\begin{array}{c}\text { Self-report } \\
\text { model }\end{array}$} & $\begin{array}{c}\text { Mixed data } \\
\text { model }\end{array}$ & $\begin{array}{c}\text { Childhood } \\
\text { model }\end{array}$ & $\begin{array}{c}\text { Adulthood } \\
\text { model }\end{array}$ \\
\hline $\begin{array}{l}\text { Direct } \\
\text { Indirect }\end{array}$ & $.22^{* *}$ & .04 & .20 & $.34^{* *}$ \\
$\begin{array}{l}\text { Total } \\
\text { Proportion of relationship } \\
\text { mediated }\end{array}$ & $.28^{* *}$ & $.22^{* *}$ & & $.16^{* *}$ & $.11^{* *}$ \\
& .56 & $.26^{* *}$ & $.36^{* *}$ & $.45^{* *}$ \\
\hline
\end{tabular}

Note. Proportion of relationship mediated was calculated by dividing the indirect relationship by the total relationship.

$* * p<.01$. 
California at Berkeley. The IGS were a combination of three studies conducted at the Institute, beginning in the early 1920s. Because, for the most part, the same measures were collected in the three studies, they were combined in the analyses. The participants included in our study were predominantly White and were roughly evenly divided between males and females. The average participant had at least some college education, and approximately $60 \%$ were born into middle-class homes. Finally, $85 \%$ of the participants were married and had an average of 2.7 children. (For a more complete description of the IGS procedures and measures, see Block, 1971, and Clausen, 1993.)

The IGS participants' personality was assessed twice during the participants' childhood-when children were approximately 13 years old and again when participants were 16 years old. Participants' personality was also assessed in adulthood-to preserve the temporal ordering of the variables, when adulthood measures of personality were used in the analyses; we used only the early adulthood personality measures, which were collected when the participants were 30-38 years old. During the course of the IGS, participants' job satisfaction was assessed with a multi-item measure once, when participants were 41-50 years old. (Because of the intensive nature of the data collection, the adult interviews took place over approximately 8-year increments.)

There were 192 individuals who had complete personality data (age 13, age 16, and ages 30-38). Of the individuals who had complete personality data, 107 also had complete job satisfaction data. Of the individuals whose personality was assessed when they were $30-38$ years old, 151 individuals also had complete job satisfaction data. Post hoc analyses indicated that the core self-evaluations for those who had incomplete data were not different from the evaluations for those who had complete data.

\section{Measures}

Core self-evaluations. On the basis of the interview transcripts and archives for each participant, expert psychologists trained in personality assessment were asked to sort 104 personality descriptors into nine categories, ranging from most descriptive to least descriptive of the participants' personality. These categories were then numbered, from 9 being the most descriptive to 1 being the least descriptive. To eliminate the possibility that assessors' subsequent personality ratings of a participant were influenced by earlier ratings, no assessor evaluated the same participant over more than one time period. Because the multiple assessors rated each participant according to the $Q$ set items, it is possible to estimate interrater reliability of the ratings. Across all assessments, the average reliabilities ranged from .72 to .78 . Thus, the assessors were reliable in their assessment of participants' personality. Participants' scores on each item were computed as the average score across the assessors.

The 104 items measured many aspects of participants' personality. Of these items, 8 met the requirements of core self-evaluations measures: (a) self-focused, (b) evaluative, and (c) carried a positive or negative affective connotation. For example, descriptions such as "Is hostile," "Is sociable," and "Is productive; gets things done" were excluded because they did not meet one or more of the evaluative criteria. Sample items from the 8-item scale include "Is self-defeating" (reverse scored), "Is satisfied with self," and "Is self-pitying" (reverse scored). Responses to these 8 items were summed to form a measure of core self-evaluations for each time period. The reliability of this scale was $\alpha=.72$ for children ages 13 and 16 , and $\alpha=.74$ for the adult assessment. Childhood core self-evaluations were assessed as the average of the age 13 and age 16 assessments, whereas adulthood core self-evaluations were assessed with the single (ages 30-38) early adulthood assessment.

Job satisfaction. Overall job satisfaction was measured when participants were 41-50 years old, with an eight-item scale that asked participants to report their satisfaction with various facets of their job (e.g., income, supervision, job security, coworkers). Interviewers coded responses on a 1 (dislike it very much) to 5 (like it very much) scale. Responses to these eight items were summed to form a measure of overall job satisfaction. The reliability of this scale was $\alpha=.92$.

Job complexity. At the same time participants' job satisfaction was measured, job complexity was measured by matching the DOT rating of job titles to the participants' jobs. The DOT evaluates job complexity in terms of complexity in dealing with people (rated on a 0-8 scale anchored by mentoring [0] and taking instructions [8]), data (rated on a $0-6$ scale anchored by synthesizing [0] and coordinating [6]), and things (rated on a $0-7$ scale anchored by setting up [0] and handling [7]). These three facets were summed $(\alpha=.72)$ to form an overall measure of job complexity. After summing the facets, the scale was reverse scored to make high scores indicate more complex jobs.

\section{Results}

Table 3 presents descriptive statistics, scale reliabilities, and intercorrelations of study variables. Correlations between study variables were consistent with Study 1 results. Specifically, core self-evaluations, measured in both childhood and early adulthood, were significantly correlated with job complexity and job satisfaction. Job complexity was also significantly correlated with job satisfaction, at a level higher than that in Study 1. Results also revealed relatively strong correlations between the childhood assessments of core self-evaluations and the early adulthood assessment. From the time individuals were teenagers to when they were in their $30 \mathrm{~s}$, the correlation between their core self-evaluations was .46 . When corrected for unreliability, this correlation rose to .62 .

\section{Structural Model Results}

We tested two models in this study. One model related the childhood assessment of core self-evaluations to job complexity and job satisfaction; the other model related the early adult assessment (ages 30-38) to these concepts. Covariance structure analysis procedures in this study were consistent with those in Study 1. LISREL estimates for the hypothesized models are provided in

Table 3

Descriptive Statistics, Scale Reliabilities, and Intercorrelations of Study 2 Variables

\begin{tabular}{lcccccc}
\multicolumn{1}{c}{ Variable } & \multicolumn{1}{c}{$\boldsymbol{M}$} & $S D$ & 1 & 2 & 3 & 4 \\
\hline 1. Core self-evaluations: childhood & 0.00 & 1.76 & 74 & & & \\
2. Core self-evaluations: ages $30-38$ & 0.00 & 1.00 & 46 & 74 & & \\
3. Job complexity & 5.21 & 2.35 & 22 & 19 & 72 & \\
4. Job satisfaction & 27.96 & 5.71 & 27 & 43 & 41 & 92 \\
\hline
\end{tabular}

Note. Decimals are omitted from correlations and reliability coefficients. Coefficient alpha reliability estimates are on the diagonal. All correlations are significant at $p<.05$. Listwise $N=107$. 
Figure 4. Results indicate that core self-evaluations had a significant relationship with job complexity in both models. However, core self-evaluations had a significant direct relationship with job satisfaction only in the early adult model (in which core evaluations were assessed when participants were ages 30-38). Results also showed that job complexity was significantly related to job satisfaction in both models. The fit statistics for the childhood model were as follows: $\chi^{2}(3, N=107)=2.70(n s)$, RSEA $=.01$, $\mathrm{GFI}=.99, \mathrm{AGFI}=.96, \mathrm{NFI}=.97, \mathrm{NNFI}=1.00, \mathrm{IFI}=1.00$, $\mathrm{RFI}=.93$, PNFI $=.48$. For the adult model, the fit statistics were as follows: $\chi^{2}(2, N=151)=0.11, n s, \mathrm{RSEA}=.01, \mathrm{GFI}=1.00$, $\mathrm{AGFI}=1.00, \mathrm{NFI}=1.00, \mathrm{NNFI}=1.00, \mathrm{IFI}=1.00, \mathrm{RFI}=1.00$, PNFI $=.67$

The last two columns of Table 2 contain the direct, indirect, and total (direct + indirect) relations of the core self-evaluations concept to job satisfaction for the childhood and adulthood models. As with Study 1, results indicated a significant indirect relationship between core self-evaluations and job satisfaction. Also similar to Study 1 , results were somewhat inconsistent regarding the direct relationship. There was also some inconsistency in the percentage of the relationship that was mediated by job characteristics. In total, results indicated that at least part of the relationship between core self-evaluations and job satisfaction was mediated by job characteristics, though the exact magnitude of the mediation is not clear.

\section{Alternative Model Tests}

In Study 2, we investigated two of the same alternative models as in Study 1 (with no direct relationship between core selfevaluations and job satisfaction and no direct relationship between job complexity and job satisfaction). For the model that dropped the link between core self-evaluations and job satisfaction, results indicated that dropping the link significantly decreased the fit of the adulthood model, $\Delta \chi^{2}(1, N=151)=13.69, p<.01$, but not the childhood model, $\Delta \chi^{2}(1, N=107)=2.82, n s$. For the model that dropped the link between job complexity and job satisfaction, results indicated that dropping this link decreased the fit of both the childhood and adulthood models, $\Delta \chi^{2}(1, N=107)=12.66$, $p<.01$, and $\Delta \chi^{2}(1, N=151)=18.81, p<.01$, respectively. The parsimony fit statistics increased for the alternative models that dropped the core self-evaluations link but decreased in the alternative models that dropped the job complexity link. Thus, as in
Study 1 , it appears that a direct link between core self-evaluations and job satisfaction is not required. However, unlike Study 1 , Study 2 results indicated that there must be a direct link between job complexity and job satisfaction for the model fit to be adequate. This was probably due to the fact that perceived job characteristics were not measured in Study 2.

\section{Discussion}

The primary contribution of these studies was to reveal that job complexity - the actual attainment of challenging jobs-was an important explanatory variable in the relationship between core self-evaluations and job satisfaction, and to show that the relationship between core self-evaluations and job satisfaction persisted over time. Brief (1998) discussed two different models of job satisfaction: top-down, in which satisfaction is derived from how one interprets one's environment, and bottom-up, in which satisfaction is derived from the experience of more positive job conditions. Previous research has supported the top-down model (Judge et al., 1998). At the same time, results of the present studies appear to support the bottom-up model. Regardless of which alternative model is adopted, core self-evaluations had a significant total relationship with job satisfaction in all four models tested, and similarly, core self-evaluations had a direct relationship with job complexity. Because job complexity, core selfevaluations, and job satisfaction were measured with independent methods and, in the case of Study 2, core self-evaluations were measured before job satisfaction (in the case of the childhood model, 30 years before job complexity and job satisfaction), confidence can be placed in the results.

Results from Study 2 indicated that core self-evaluations were related to job satisfaction over time. As is to be expected, the relationship was stronger when core evaluations were measured in adulthood, but it is impressive that independent childhood assessments correlated with job satisfaction 30 years later. Only one previous study (Staw et al., 1986) has related IGS data to job satisfaction, and similar results were found with respect to Staw et al.'s measure of affective disposition, which they acknowledged to have some conceptual ambiguities. However, Staw et al. did not link personality to job complexity.

Results from Study 2 also provided insight into the stability of the core self-evaluations concept. Research on the Big Five personality traits suggests that the average correlation between the

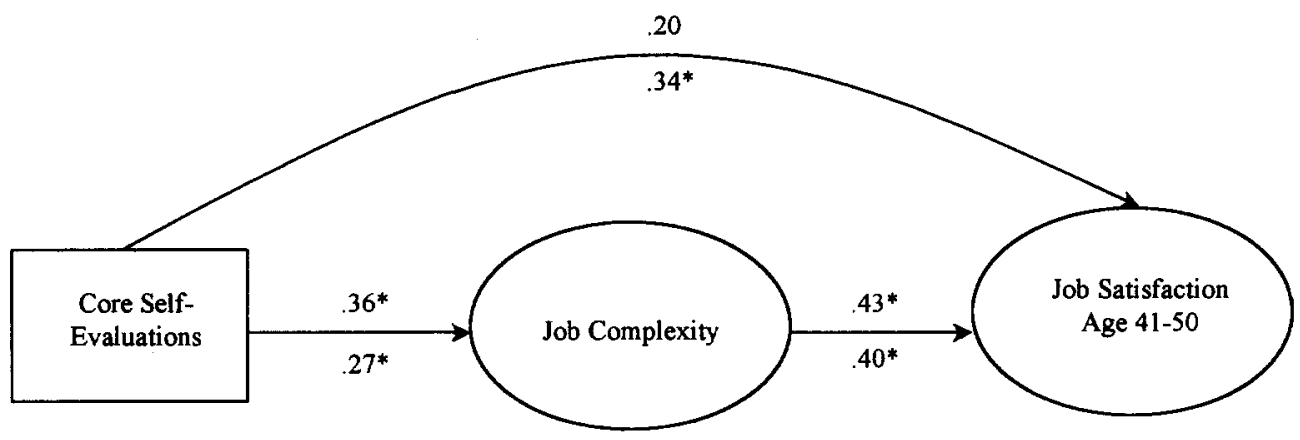

Figure 4. LISREL results - Study 2. Estimates in top row represent results using childhood personality ratings; estimates in bottom row represent results using early adult (ages $30-38$ ) personality ratings. ${ }^{*} p<.01$. 
traits is .58 over roughly the same time period ( 20 years) as that in Study 2 (Costa \& McCrae, 1994). The stability of core selfevaluations in Study 2 was somewhat lower: .46 (.62 when corrected for unreliability). The slightly lower stability may be due to the fact that the time interval included an individual's formative years (whereas Costa \& McCrae's, 1994, data only considered stability in adult personality), or it may be due to the fact that some traits may be somewhat less stable than others (House et al., 1996). Thus, although the stability of core self-evaluations is moderately high, it is not so high to suggest that it is immutable to change. We are aware of no previous research on the stability of the core self-evaluations concept, so future research should explore this issue further.

Some degree of confidence can be placed in the interpretation of our results because we used independent sources of data to eliminate response-response bias and a longitudinal design to support the assumed causal ordering of the variables. However, with respect to several important aspects of the model, causal inferences cannot be drawn. Specifically, it is just as likely that the hypothesized link from perceived job characteristics to job satisfaction is also (or instead) in the opposite direction, from job satisfaction to perceived job characteristics. Ideally, we would have tested a nonrecursive model that tested a reciprocal relationship between the two concepts, something that has been done in past research (James \& Jones, 1980; James \& Tetrick, 1986). Unfortunately, such tests require a number of instrumental variables that uniquely influence each concept; it was not possible to use such variables in this study. Thus, little weight can be placed on the hypothesized causal ordering of the perceived job characteristics-job satisfaction relationship. For this reason, the results involving perceived job characteristics are merely exploratory. Only experimental studies involving core self-evaluations, perceived task characteristics, and task satisfaction would confirm the hypothesized causal structure.

More weight can be placed on the relationship between core self-evaluations and job complexity, which is where the unique contribution of this study lies. For the first time, it has been shown that part of the reason individuals with positive core selfevaluations perceive more challenging jobs and report higher levels of job satisfaction is that they actually have obtained more complex (and thus more challenging and intrinsically enriching) jobs. Judge et al.'s (1997) theory of core evaluations suggests three possible paths from core self-evaluations to job satisfaction: direct, indirect through job attribute perceptions, and indirect through on-the-job actions taken to make the job more rewarding (e.g., showing initiative). This study provides the first general support for the action mediator.

Correlations between self- and significant-other reports of core self-evaluations in Study 1 were far from perfect (the mean corrected correlation between the core traits was .49), and self-reports of core self-evaluations had a higher relationship with job satisfaction than the significant-other reports. One might question the use of significant-other reports for self-evaluations. Whereas an individual's own core self-evaluations can be perceived directly, from the perspective of others they must be inferred. However, errors can be made in both cases. On the one hand, self-reports may not be completely accurate because of the possibility of self-enhancement. Further, in this case, self-reports also introduce the possibility of response-response bias in the results. On the other hand, significant-other reports may be less accurate because significant others have no opportunity to directly observe the type of internal trait we were measuring with self-evaluations.

Use of peer reports is a common practice in personality research. As noted by Funder and Colvin (1997), one of the reasons researchers study self-other agreement is to investigate the degree to which self-enhancement or self-serving biases affect self-reports of personality. Although this area continues to be investigated, evidence does suggest that some degree of self-enhancement occurs (Funder \& Colvin, 1997). For this reason, we assessed core self-evaluations with both self-reports and other reports, though the latter certainly have limitations of their own. As Costa and McCrae (1992) noted, the joint inclusion of self-reports and other reports provides valuable information, particularly when the sources produce mostly equivalent results. In the case of Study 1 , there are some differences in the results of the self- and otherreport models.

It is possible that the best way to assess another person's core self-evaluations would be a clinical interview, and this is what we did in Study 2. It is interesting to note that, across the two studies, all three sources of data (self-, significant-other, and clinical ratings) produced generally similar results-in all cases, core selfevaluations were significantly related to both job satisfaction and job complexity. Because the sources are not purely equivalent, we think future research should continue to use multiple sources of core self-evaluations. However, it would also be useful for future research to model the causes of agreement and disagreement among the sources of core self-evaluations data. This mimics a more general call for more research on the causes and meaning of self-other agreement recently voiced by Funder and Colvin (1997).

In interpreting the results of the present studies, it is important to note that job complexity had a direct relationship with job satisfaction only in Study 2. This should not be surprising considering that virtually all of the effects of environmental conditions are mediated by conscious perceptions (although there could be subconscious mechanisms involved in some cases). However, a cautionary note should be sounded here. Although the measure of job complexity was correlated with perceptions, it is not a complete measure. A job title or brief job description does not provide a detailed picture of a job's characteristics because jobs with the same title can be very different. As House et al. (1996) noted, the somewhat imprecise measurement of job complexity makes it more difficult to find associations with other variables. Thus, the imperfections in our measure of job complexity suggest that the results might be conservative. It would be useful for future research to investigate whether individuals with a positive selfconcept attain more complex job duties within the same type of job.

The response rate for Study 1 is a limitation of the study. Because the majority of individuals receiving surveys did not respond, it raises the question of whether the same relationships would be observed if all individuals had responded. Viswesvaran, Barrick, and Ones (1995) developed a methodology to determine the response level of nonrespondents that would invalidate the conclusions on the basis of the survey of respondents. Using their formula, we estimated that the correlation between core selfevaluations and job satisfaction among nonrespondents would have to be .03 to render the correlations that were observed ( .41 for 
self-reported core self-evaluations, .19 for significant-other reported core evaluations; see Table 1) nonsignificant. The nonrespondent correlation between core self-evaluations and job complexity that would render the observed correlation nonsignificant is .09. Because both of these values are well below the observed correlations (see Table 1), the relationships among nonrespondents would have to be quite different than those that were observed in this study. Furthermore, the representativeness of the sample-all data were collected from residents of a single Midwestern city-is a limitation. It is critical that future research replicate these results with more diverse, particularly international, samples.

Future studies should attempt to build on the theory of core evaluations offered by Judge et al. (1998). Although our findings demonstrate a relationship between core self-evaluations and job complexity (and thus extend previous findings that considered only perceptions of job characteristics), they do not shed light on the processes leading to the relationship. There are a number of mechanisms that may link core self-evaluations to job complexity. Job choice was one of the actions specifically mentioned by Judge et al. (1997). People who are generally confident in themselves should be more likely to think they can get challenging jobs. People with high self-esteem also tend to have better social networks and make more favorable impressions on others (Locke, McClear, \& Knight, 1996), enhancing their ability to obtain complex jobs. Other possible mechanisms linking core self-evaluations and job complexity include job behaviors such as goal setting, goal commitment, effort and tenacity in the face of setbacks, and coping with negative events at work. Other actions that might assist positively disposed individuals in obtaining complex jobs include efforts to improve one's skills and to exercise leadership. Finally, given the link between core self-evaluations and job complexity found in two separate studies here, and given the somewhat inexact measurement of job complexity, more work is needed on the construct validity of job complexity. Thus, although the present study extends recent work on core self-evaluations, there is a need for further extension.

\section{References}

Adelmann, P. K. (1987). Occupational complexity, control, and personal income: Their relation to psychological well-being in men and women. Journal of Applied Psychology, 72, 529-537.

Anderson, C. R. (1977). Locus of control, coping behaviors, and performance in a stress setting: A longitudinal study. Journal of Applied Psychology, 62, 446-451.

Anderson, J. C., \& Gerbing, D. W. (1988). Structural equation modeling in practice: A review and recommended two-step approach. Psychological Bulletin, 103, 411-423.

Arvey, R. D., Bouchard, T. J., Segal, N. L., \& Abraham, L. M. (1989). Job satisfaction: Environmental and genetic components. Journal of Applied Psychology, 74, 187-192.

Bandura, A. (1997). Self-efficacy: The exercise of control. New York: Freeman.

Block, J. (1971). Lives through time. Berkeley, CA: Bancroft Books.

Brayfield, A. H., \& Rothe, H. F. (1951). An index of job satisfaction. Journal of Applied Psychology, 35, 307-311.

Brief, A. P. (1998). Attitudes in and around organizations. Thousand Oaks, CA: Sage

Brief, A. P., Butcher, A., \& Roberson, L. (1995). Cookies, disposition, and job attitudes: The effects of positive mood inducing events and negative affectivity on job satisfaction in a field experiment. Organizational Behavior and Human Decision Processes, 62, 55-62.

Cain, P. S., \& Green, B. F. (1983). Reliabilities of selected ratings available from the Dictionary of Occupational Titles. Journal of Applied Psychology, 68, 155-165.

Clausen, J. A. (1993). American lives: Looking back at the children of the Great Depression. New York: Free Press.

Costa, P. T., Jr., \& McCrae, R. R. (1994). Set like plaster? Evidence for the stability of adult personality. In T. F. Heatherton \& J. L. Weinberger (Eds.), Can personality change? (pp. 21-40). Washington, DC: American Psychological Association.

Diener, E., Larsen, R. J., \& Emmons, R. A. (1984). Person $\times$ Situation interactions: Choice of situations and congruence response models. Journal of Personality and Social Psychology, 47, 580-592.

Dunham, R. B. (1976). The measurement and dimensionality of job characteristics. Journal of Applied Psychology, 61, 404-409.

Dunham, R. B., Aldag, R. J., \& Brief, A. P. (1977). Dimensionality of task design as measured by the Job Diagnostic Survey. Academy of Management Journal, 20, 209-223.

Eysenck, H. J., \& Eysenck, S. B. G. (1968). Manual for the Eysenck Personality Inventory. San Diego, CA: Educational and Industrial Testing Service.

Fried, Y., \& Ferris, G. R. (1987). The validity of the job characteristics model: A review and meta-analysis. Personnel Psychology, 40, 287322.

Funder, D. C., \& Colvin, C. R. (1997). Congruence of others' and selfjudgments of personality. In R. Hogan, J. Johnson, \& S. Briggs (Eds.), Handbook of personality psychology (pp. 617-647), San Diego, CA: Academic Press.

Gerhart, B. A. (1985). Sources of variance in perceptions of job complexity. Unpublished doctoral dissertation, University of Wisconsin-Madison.

Gerhart, B. (1987). How important are dispositional factors as determinants of job satisfaction? Implications for job design and other personnel programs. Journal of Applied Psychology, 72, 366-373.

Gerhart, B. (1988). Sources of variance in incumbent perceptions of job complexity. Journal of Applied Psychology, 73, 154-162.

Glick, W. H., Jenkins, G. D., Jr., \& Gupta, N. (1986). Method versus substance: How strong are underlying relationships between job characteristics and attitudinal outcomes? Academy of Management Journal, 29, 441-464.

Hacket, G., \& Betz, N. E. (1981). A self-efficacy approach to the career development of women. Journal of Vocational Behavior, 18, 326-339.

Hackman, J., \& Oldham, G. (1980). Work redesign. Reading, MA: Addison-Wesley.

Hall, D. T., \& Foster, L. W. (1977). A psychological success cycle and goal setting: Goals, performance, and attitudes. Academy of Management Journal, 20, 282-290.

House, R. J., Shane, S. A., \& Herold, D. M. (1996). Rumors of the death of dispositional research are vastly exaggerated. Academy of Management Review, 21, 203-224.

James, L. R., \& Jones, A. P. (1980). Perceived job characteristics and job satisfaction: An examination of reciprocal causation. Personnel Psychology, 33, 97-135.

James, L. R., \& Tetrick, L. E. (1986). Confirmatory analytic tests of three causal models relating job perceptions to job satisfaction. Journal of Applied Psychology, 71, 77-82.

Jöreskog, K. G., \& Sörbom, D. (1989). LISREL 7: A guide to the program and applications. Chicago: SPSS.

Jöreskog, K. G., \& Sörbom, D. (1993). LISREL 8 user's reference guide. Chicago: Scientific Software.

Judge, T. A., Boudreau, J. W., \& Bretz, R. D. (1994). Job and life attitudes of male executives. Journal of Applied Psychology, 79, 767-782.

Judge, T. A., Locke, E. A., \& Durham, C. C. (1997). The dispositional 
causes of job satisfaction: A core evaluations approach. Research in Organizational Behavior, 19, 151-188.

Judge, T. A., Locke, E. A., Durham, C. C., \& Kluger, A. N. (1998). Dispositional effects on job and life satisfaction: The role of core evaluations. Journal of Applied Psychology, 83, 17-34.

Kraiger, K., Billings, R. S., \& Isen, A. M. (1989). The influence of positive affective states on task perceptions and satisfaction. Organizational Behavior and Human Decision Processes, 44, 12-25.

Larsen, R. J., \& Ketelaar, T. (1991). Personality and susceptibility to positive and negative emotional states. Joumal of Personality and Social Psychology, 61, 132-140.

Levenson, H. (1981). Differentiating among internality, powerful others, and chance. In H. M. Lefcourt (Ed.), Research with the locus of control construct (pp. 15-63). New York: Academic Press.

Levy, P. E., \& Baumgardner, A. H. (1991). Effects of self-esteem and gender on goal choice. Journal of Organizational Behavior, 12, 529541.

Locke, E. A., McClear, K., \& Knight, D. (1996). Self-esteem and work. International Review of Industrial \& Organizational Psychology, 11, 1-32.

Loher, B. T., Noe, R. A., Moeller, N. L., \& Fitzgerald, M. P. (1985). A meta-analysis of the relation of job characteristics to job satisfaction. Journal of Applied Psychology, 70, 280-289.

Magnus, K., Diener, E., Fujita, F., \& Pavot, W. (1993). Extraversion and neuroticism as predictors of objective life events: A longitudinal analysis. Journal of Personality and Social Psychology, 65, 1046-1053.

Magnusson, D. (1990). Personality development from an interactional perspective. In L. A. Pervin (Ed.), Handbook of personality (pp. 193222). New York: Guilford Press.

Medsker, G. J., Williams, L. J., \& Holahan, P. J. (1994). A review of current practices for evaluating causal models in organizational behavior and human resources management research. Joumal of Management, 20 , 439-464.

Motowidlo, S. J. (1996). Orientation toward the job and organization. In K. R. Murphy (Ed.), Individual differences and behavior in organizations (pp. 175-208). San Francisco: Jossey Bass.
Necowitz, L. B., \& Roznowski, M. (1994). Negative affectivity and job satisfaction: Cognitive processes underlying the relationship and effects on employee behaviors. Journal of Vocational Behavior, 45, 270-294.

Roos, P. A., \& Treiman, D. J. (1980). Worker functions and worker traits for the 1970 U.S. census classification. In A. R. Miller, D. J. Treiman, P. S. Cain, \& P. A. Roos (Eds.), Work, jobs, and occupations: A critical review of the Dictionary of Occupational Titles (pp. 336-389). Washington, DC: National Academy Press.

Rosenberg, M. (1965). Society and the adolescent self-image. Princeton, NJ: Princeton University Press.

Scarpello, V., \& Campbell, J. P. (1983). Job satisfaction: Are all the parts there? Personnel Psychology, 36, 577-600.

Spector, P. E. (1982). Behavior in organizations as a function of employee's locus of control. Psychological Bulletin, 91, 482-497.

Spector, P. E., \& Jex, S. M. (1991). Relations of job characteristics from multiple data sources with employee affect, absence, turnover intentions, and health. Journal of Applied Psychology, 76, 46-53.

Staw, B. M., Bell, N. E., \& Clausen, J. A. (1986). The dispositional approach to job attitudes: A lifetime longitudinal test. Administrative Science Quarterly, 31, 56-77.

Swann, W. B., Jr., Stein-Seroussi, A., \& Giesler, R. B. (1992). Why people self-verify. Joumal of Personality and Social Psychology, 62, 392-401.

Viswesvaran, C., Barrick, M. R., \& Ones, D. S. (1995). How definitive are conclusions based on survey data: Estimating robustness to nonresponse. Personnel Psychology, 46, 551-567.

Weiss, H. M., \& Cropanzano, R. (1996). Affective events theory: A theoretical discussion of the structure, causes, and consequences of affective experiences at work. Research in Organizational Behavior, 18 $1-74$.

Received June 24, 1998

Revision received May 8, 1999

Accepted May 8, 1999 